DOI: $10.1002 /(($ please add manuscript number $))$

Article type: Full Paper

\title{
Revealing the pseudo-intercalation charge storage mechanism of MXenes in acidic electrolyte
}

Xinpeng Mu, Dashuai Wang, Fei Du, Gang Chen, Chunzhong Wang, Yingjin Wei, Yury Gogotsi*, Yu Gao*, Yohan Dall'Agnese*

X. Mu, D. Wang, Prof. F. Du, Prof. G. Chen, Prof. C. Wang, Prof. Y. Wei, Prof. Y. Gogotsi, Prof. Y. Gao, Prof. Y. Dall'Agnese

Key Laboratory of Physics and Technology for Advanced Batteries (Ministry of Education), College of Physics, Jilin University, Changchun 130012, PR China

E-mail: yugao@jlu.edu.cn

Prof. F. Du, Prof. G. Chen

State Key Laboratory of Superhard Materials, Jilin University, Changchun 130012, PR China

Prof. Y. Gogotsi

A. J. Drexel Nanomaterials Institute, and Department of Materials Science and Engineering, Drexel University, Philadelphia, Pennsylvania 19104, United States

Email: gogotsi@drexel.edu

Dr. Y. Dall'Agnese

Institute for Materials Discovery, University College London, London WC1E 7JE, United Kingdom

Email: y.dallagnese@ucl.ac.uk

Keywords: MXenes, two-dimensional materials, supercapacitors, in-situ X-ray diffraction, density functional theory

\begin{abstract}
Since the discovery of $\mathrm{Ti}_{3} \mathrm{C}_{2} \mathrm{~T}_{\mathrm{x}}$ in 2011 , the family of $2 \mathrm{D}$ transition metal carbides, carbonitrides and nitrides (collectively known as MXenes) has quickly attracted the attention of those developing energy storage applications such as electrodes for supercapacitors with acidic aqueous electrolytes. The excellent performance of these MXenes was attributed to a pseudocapacitive energy storage mechanism, based on the non-rectangular shape of cyclic voltammetry curves and changes in the titanium oxidation state detected by in-situ X-ray absorption spectroscopy. However, the pseudocapacitive mechanism was not well understood
\end{abstract}


and no dimensional changes due to proton insertion have been reported. In this work, we used in-situ X-ray diffraction and density functional theory to investigate the charge storage mechanism of $\mathrm{Ti}_{3} \mathrm{C}_{2} \mathrm{~T}_{\mathrm{x}}$ in $1 \mathrm{M} \mathrm{H}_{2} \mathrm{SO}_{4}$. Results revealed that an $0.5 \AA$ expansion and shrinkage of the $c$-lattice parameter of $\mathrm{Ti}_{3} \mathrm{C}_{2} \mathrm{~T}_{\mathrm{x}}$ occurs during cycling in a $0.9 \mathrm{~V}$ voltage window, showing that the charge storage mechanism is intercalation pseudocapacitance with implication for MXene use in energy storage and electrochemical actuators.

\section{Introduction}

With the increasing demand for sustainable and portable energy, supercapacitors have attracted more attention due to their greater power densities than batteries. ${ }^{[1]}$ However, electrical double layer capacitors (which are the conventional type of supercapacitors) have a limited energy density due to charge storage mechanism limited to the electrosorption of ions on porous carbon electrodes. The other kind of supercapacitors, called pseudocapacitors, provide higher energy densities due to redox reactions, but have generally shorter cycle life and are more expensive. Conway describes pseudocapacitance as either one of the three faradaic mechanisms that exhibit capacitive electrochemical behavior. ${ }^{[2]}$ The first pseudocapacitance mechanism is underpotential deposition, or metal ions or protons forming an adsorbed monolayer at a different metal's surface above their redox potential. The second case is redox capacitance, which is the electrochemical adsorption of ions onto the surface or near surface of a material with a concomitant faradaic charge-transfer. The third case is intercalation capacitance, which is the fast faradaic intercalation of ions into tunnels or layers of electrode materials.

Recently, a new family of 2D materials called MXenes has been discovered. ${ }^{[3]}$ MXenes have a layered structure composed of multiple elements with the general formula $M_{n+1} X_{n}$, in which $\mathrm{M}$ is an early transition metal and $\mathrm{X}$ is carbon and/or nitrogen. As of today, more than 30 different MXenes have been synthesized. ${ }^{[4]}$ The main interest in MXenes for energy storage applications is that these materials contain a carbide core that guarantees electronic conductivity 
and a transition metal oxide-like surface that can undergo redox reactions. MXenes are promising materials for electrochemical energy storage. In particular, $\mathrm{Ti}_{3} \mathrm{C}_{2} \mathrm{~T}_{\mathrm{x}}\left(\mathrm{T}_{\mathrm{x}}=\mathrm{O}, \mathrm{OH}, \mathrm{F}\right.$ surface termination) as an electrode for supercapacitors exhibit high gravimetric and volumetric capacitances in a wide variety of electrolytes. ${ }^{[5]}$

For achieving high-performance rechargeable energy storage devices, it is vital to study and understand the physical and chemical changes in electrode materials upon cycling. The charge storage mechanism of $\mathrm{Ti}_{3} \mathrm{C}_{2} \mathrm{~T}_{\mathrm{x}}$ in various electrolytes was tested by several in-situ techniques. In the first report on MXenes for supercapacitors application, researchers used in-situ X-ray diffraction (XRD). The report revealed that $\mathrm{Na}^{+}, \mathrm{K}^{+}$and $\mathrm{Mg}^{2+}$ (from $\mathrm{CH}_{3} \mathrm{COONa}, \mathrm{KOH}$ and $\mathrm{MgSO}_{4}$ solutions, respectively) were intercalated and deintercalated between $\mathrm{Ti}_{3} \mathrm{C}_{2} \mathrm{~T}_{\mathrm{x}}$ layers during electrochemical reaction, as demonstrated by the expansion and contraction of the lattice. ${ }^{[6]}$ In-situ XRD later revealed the intercalation charge storage mechanisms of $\mathrm{Ti}_{3} \mathrm{C}_{2} \mathrm{~T}_{\mathrm{x}}$ in 1-ethly-3-methylimidazolium bis- (trifluoromethylsulfonyl)-imide. ${ }^{[7]}$ Although the best electrochemical performance of MXene was obtained in $\mathrm{H}_{2} \mathrm{SO}_{4},{ }^{[8]}$ in-situ XRD analysis was never reported for this system.

Electrochemical quartz crystal admittance was used in a variety of aqueous electrolytes with different cations $\left(\mathrm{Li}^{+}, \mathrm{Na}^{+}, \mathrm{K}^{+}, \mathrm{Cs}^{+}, \mathrm{Mg}^{2+}, \mathrm{Ca}^{2+}, \mathrm{Ba}^{2+}\right.$, and three tetra-alkylammonium cations) to observe that cation insertion is accompanied by electrode deformations (expansion/contraction), facilitated by the presence of water molecules. ${ }^{[9]}$ Electrochemical insitu X-ray absorption spectroscopy measurements detected a change in the Ti oxidation state, from +2.34 to +2.43 upon cycling from $-0.35 \mathrm{~V}$ to $0.35 \mathrm{~V}$ vs. $\mathrm{Ag} / \mathrm{AgCl}$ in $\mathrm{H}_{2} \mathrm{SO}_{4} \cdot{ }^{[10]}$ In-situ Raman measurements demonstrated that, in $\mathrm{H}_{2} \mathrm{SO}_{4}$ solution, hydronium ions from the electrolyte reversibly bond/debond with the terminal $\mathrm{O}$ during electrochemical reduction/oxidation, respectively. ${ }^{[1]}$ Besides, density functional theory (DFT) was used to develop a theoretical model to describe the pseudocapacitive behavior of $\mathrm{Ti}_{3} \mathrm{C}_{2} \mathrm{~T}_{\mathrm{x}}$ in $\mathrm{H}_{2} \mathrm{SO}_{4}$ electrolyte $^{[12]}$ and cations adsorption on MXenes with different terminations. ${ }^{[13]}$ 
Excellent electrochemical performances were achieved with $\mathrm{Ti}_{3} \mathrm{C}_{2} \mathrm{~T}_{\mathrm{x}}$-based electrodes in $\mathrm{H}_{2} \mathrm{SO}_{4}$. In the first report on capacitive behavior of $\mathrm{Ti}_{3} \mathrm{C}_{2} \mathrm{~T}_{\mathrm{x}}$ in sulfuric acid, the capacitance was up to $520 \mathrm{~F} \mathrm{~cm}^{-3}$ and $325 \mathrm{~F} \mathrm{~g} \mathrm{~g}^{-1} \cdot{ }^{[14]}$ Later work further improved the performance, notably $\mathrm{Ti}_{3} \mathrm{C}_{2} \mathrm{~T}_{\mathrm{x}}$ hydrogel reached volumetric capacitance of up to $1,500 \mathrm{~F} \mathrm{~cm}^{-3}$ and macroporous $\mathrm{Ti}_{3} \mathrm{C}_{2} \mathrm{~T}_{\mathrm{x}}$ film in $\mathrm{H}_{2} \mathrm{SO}_{4}$ delivered up to $210 \mathrm{~F} \mathrm{~g}^{-1}$ at high rate of $10 \mathrm{~V} \mathrm{~s}^{-1}$, surpassing the best carbon supercapacitors known and reaching $\mathrm{RuO}_{2}$ pseudocapacitors performance. ${ }^{[8]}$ The electrochemical reaction is proposed to follow Equation 1:

$$
T i_{3} C_{2} O_{x}(O H)_{y} F_{z}+\delta H^{+} \leftrightarrow T i_{3} C_{2} O_{x-\delta}(O H)_{y+\delta} F_{z}
$$

Until now, researchers believed that there was no change in $c$-lattice parameter upon cycling in acidic electrolytes due to the small size of proton. ${ }^{[14]}$ Indeed, proton intercalation mechanism into MXene has not been thoroughly studied. Our work reveals by in-situ XRD that the pseudointercalation mechanism of $\mathrm{H}^{+}$insertion between $\mathrm{Ti}_{3} \mathrm{C}_{2} \mathrm{~T}_{x}$ layers leads to lattice parameter change, despite the small size of protons, and correlates it to density functional theoretical (DFT) calculations.

\section{Results and Discussion}

Figure 1a shows the XRD patterns of dried $\mathrm{Ti}_{3} \mathrm{C}_{2} \mathrm{~T}_{\mathrm{x}}$ electrode compared to the $\mathrm{Ti}_{3} \mathrm{C}_{2} \mathrm{~T}_{\mathrm{x}}$ electrode immersed in $1 \mathrm{M} \mathrm{H}_{2} \mathrm{SO}_{4}$. The positions of the (002) peaks are proportional to the $c$ lattice parameter according to the Bragg's equation. For layered materials, the change of $c$ lattice parameter is equivalent to the change of interlayer spacing and the change of bond distance. When immersed in the electrolyte, the peak shifted, corresponding to an $3.04 \AA$ increase of the $c$-lattice parameter, which is often attributed to intercalation of $\mathrm{H}_{2} \mathrm{O}$ molecules or solvated ions, increasing the interlayer distance, and is coherent with previous reports. ${ }^{[15]}$

Figure $1 \mathrm{~b}$ presents the cyclic voltammograms of $\mathrm{Ti}_{3} \mathrm{C}_{2} \mathrm{~T}_{\mathrm{x}}$ obtained in $1 \mathrm{M} \mathrm{H}_{2} \mathrm{SO}_{4}$ electrolyte at $0.2 \mathrm{mV} \mathrm{s}^{-1}$. The open circuit potential (OCV) was $-0.30 \mathrm{~V} \mathrm{vs.} \mathrm{Ag} \mathrm{(silver} \mathrm{wire).} \mathrm{At} \mathrm{potentials}$ lower than $-0.9 \mathrm{~V}$ vs $\mathrm{Ag}$, visible hydrogen evolution reaction occurred and deteriorated $\mathrm{Ti}_{3} \mathrm{C}_{2} \mathrm{~T}_{\mathrm{x}}$ 
adhesion to the glassy carbon electrode, therefore limiting the voltage window for application. Due to the slower rate used here than in previous reports, the broad peaks are more pronounced in our data. Specifically, two sets of redox peaks can be distinguished in Figure $1 \mathrm{~b}$. The oxidation peak at $-0.556 \mathrm{~V}(\mathrm{~A})$ and reduction peak at $-0.700 \mathrm{~V}(\mathrm{~B})$ could be attributed to a first redox couple, while the oxidation peak at $-0.361 \mathrm{~V}(\mathrm{C})$ and reduction peak at $-0.400 \mathrm{~V}$ (D) would correspond to a second redox couple.

In-situ XRD was used to investigate the electrochemical behavior of $\mathrm{Ti}_{3} \mathrm{C}_{2} \mathrm{~T}_{\mathrm{x}}$ upon cycling in $1 \mathrm{M} \mathrm{H}_{2} \mathrm{SO}_{4}$. Figure 1c represents the contour maps of in-situ XRD patterns collected in the range $2 \theta=5-20^{\circ}$ during cyclic voltammetry. A clear shift of (002) and (006) is visible during cycling. Throughout this process, no new peaks appeared, and therefore no phase change occurred. The two first cycles are irreversible, which may be due to formation of a pillared structure or modification of the surface termination. Figure 1d and 1e show the XRD patterns and the change of the $c$-lattice parameter depending on the potential during the 3rd cycle (additional cycles are shown in Figure S1). Compared to the previous report of cation intercalation into $\mathrm{Ti}_{3} \mathrm{C}_{2} \mathrm{~T}_{\mathrm{x}},{ }^{[6]}$ which showed reversible and continuous shifts, the mechanism of $\mathrm{H}^{+}$intercalation appears to be more complex. There was both shrinkage and expansion of the $c$-lattice parameter during a single charge or a single discharge. For example, during the $3^{\text {rd }}$ cycle charge, the $c$-lattice parameter remained nearly constant at $28.54 \AA$ from -0.9 to $-0.7 \mathrm{~V}$ vs. Ag, then shrank quickly to $28.07 \AA$ from -0.7 to $-0.4 \mathrm{~V} v s$. Ag, then expanded continuously to $28.22 \AA$ until $0 \mathrm{~V}$ vs. Ag. During the $3^{\text {rd }}$ cycle discharge, the $c$-lattice parameter decreased back to $28.11 \AA$ from 0 to $-0.6 \mathrm{~V} v s$. Ag, then continuously increased to reach $28.61 \AA$ at -0.9 V vs. Ag. The $c$-lattice parameters therefore changed up to $0.54 \AA$ during this single cycle, which is a larger change than in all other aqueous electrolytes previously studied. ${ }^{[6]} \mathrm{H}^{+}$is a smaller cation than the others tested $\left(\mathrm{Na}^{+}, \mathrm{Mg}^{2+}\right.$ and $\mathrm{K}^{+}$), but the capacitance in $\mathrm{H}_{2} \mathrm{SO}_{4}$ is the highest. ${ }^{[8]}$ A larger number of $\mathrm{H}^{+}$intercalated probably explains the larger volume change. 
The general trend appearing from all cycles is that no change or slight decrease in the lattice parameter upon charging occurred initially, followed by significant shrinkage/expansion phenomenon occurring below $-0.5 \mathrm{~V} v s$. Ag, with a $c$-lattice parameter change exceeding 0.4 $\AA$, whereas a smaller $(\approx 0.15 \AA)$ and opposite expansion/shrinkage phenomenon occurred at potential higher than $-0.5 \mathrm{~V}$ vs. Ag. Interestingly, this behavior change was measured at potentials corresponding to the broadest redox peaks (A and B). A possible explanation for the behavior at potential higher than $-0.5 \mathrm{~V}$ is that the positively charged $\mathrm{H}^{+}$intercalated in between negatively charged $\mathrm{Ti}_{3} \mathrm{C}_{2} \mathrm{~T}_{\mathrm{x}}$ layers increase the electrostatic attraction between layers, as it was proposed in neutral and basic electrolytes. ${ }^{[6,16]}$ The greater change observed below $-0.5 \mathrm{~V} v s$. Ag may be due redox of the $\mathrm{Ti}=\mathrm{O}$ bond on the surface of MXene by protons, leading to an increase in the bond length after $\mathrm{OH}$ formation and a steric effect, with the larger number of $\mathrm{H}^{+}$ intercalated during the faradaic process. In neutral and basic electrolytes previously investigated via in-situ $\mathrm{XRD},{ }^{[6]}$ the capacitances are inferior to $\mathrm{H}_{2} \mathrm{SO}_{4}$, meaning that other cations don't produce the same redox effect. It has also been shown that cosmotropic cations $\left(\mathrm{Li}^{+}, \mathrm{Mg}^{2+}\right.$, and $\mathrm{Al}^{3+}$ ) are inserted into the MXene interspaces in their partially hydrated form, in contrast to the insertion of chaotropic cations $\left(\mathrm{Cs}^{+}\right.$and tetrathylammonium $\left.{ }^{+}\right)$, which effectively dehydrate the MXene. ${ }^{[17]}$ Thus, the nature of the ion strongly affects changes in the interlayer spacing.

DFT calculations were performed to further investigate the lattice deformation upon intercalation of protons. Simulations were performed using two $\mathrm{Ti}_{3} \mathrm{C}_{2} \mathrm{~T}_{\mathrm{x}} 3 \times 3 \times 2$ supercells models. One was $\mathrm{Ti}_{3} \mathrm{C}_{2}$ with oxygen termination, i.e. $\mathrm{Ti}_{3} \mathrm{C}_{2} \mathrm{O}_{2}$, and the other was $\mathrm{Ti}_{3} \mathrm{C}_{2}$ with hydroxyl termination, i.e. $\mathrm{Ti}_{3} \mathrm{C}_{2}(\mathrm{OH})_{2}$. Calculations estimated that the $c$-lattice parameter of the former was $19.56 \AA$ while it was $25.77 \AA$ for the latter, which is closer to the experimental value measured by XRD (24.73 $\AA$ ). According to Figure 1a the experimental $c$-lattice parameter of $\mathrm{Ti}_{3} \mathrm{C}_{2} \mathrm{~T}_{\mathrm{x}}$ immerged in water and sulfuric acid was measured to be around $27.8 \AA$, thus $\mathrm{H}_{2} \mathrm{O}$ was inserted in the supercells until the $c$-lattice parameter reached a similar value. After insertion of 
$24 \mathrm{H}_{2} \mathrm{O}$ into the supercells $\left(1.33 \mathrm{H}_{2} \mathrm{O}\right.$ molecules per $\left.\mathrm{Ti}_{3} \mathrm{C}_{2} \mathrm{~T}_{2}\right)$, the $c$-lattice parameters of $\mathrm{Ti}_{3} \mathrm{C}_{2} \mathrm{O}_{2}$ and $\mathrm{Ti}_{3} \mathrm{C}_{2}(\mathrm{OH})_{2}$ increased to $29.42 \AA$ and $30.50 \AA$ respectively, as illustrated in Figure 2.

To better understand the $\mathrm{H}^{+}$intercalation/de-intercalation mechanism occurring in energy storage application, increasing amounts of $\mathrm{H}^{+}$were intercalated into the supercells containing 1.33 water molecules. The $\mathrm{H}_{2} \mathrm{O}$ content was kept constant throughout to focus on the effect of $\mathrm{H}^{+}$. Note that the capacitance of $\mathrm{Ti}_{3} \mathrm{C}_{2} \mathrm{~T}_{\mathrm{x}}$ with $\mathrm{H}_{2} \mathrm{SO}_{4}$ electrolyte was reported to be around 450 $\mathrm{F} \mathrm{g}^{-1},{ }^{[8]}$ which corresponds to approximately $0.84 \mathrm{H}^{+}$per $\mathrm{Ti}_{3} \mathrm{C}_{2} \mathrm{~T}_{\mathrm{x}}$, as calculated using equation 2. Figure 3a and $\mathbf{3 b}$ show the calculated $c$-lattice parameter depending on the number of $\mathrm{H}^{+}$ intercalated into supercells. $\mathrm{Ti}_{3} \mathrm{C}_{2}(\mathrm{OH})_{2}\left(\mathrm{H}_{2} \mathrm{O}\right)_{1.33}$ and $\mathrm{Ti}_{3} \mathrm{C}_{2} \mathrm{O}_{2}\left(\mathrm{H}_{2} \mathrm{O}\right)_{1.33}$ exhibited drastically different evolution. Upon $\mathrm{H}^{+}$intercalation into the $\mathrm{Ti}_{3} \mathrm{C}_{2} \mathrm{O}_{2}\left(\mathrm{H}_{2} \mathrm{O}\right)_{1.33}$ supercell, the general trend is that the $c$-lattice parameter decreases, with the most significant decrease occurring from 0 to $0.33 \mathrm{H}^{+}$. The $c$-lattice parameter shrinks by $1.08 \AA$ when $20 \mathrm{H}^{+}$are intercalated (i.e., $1.11 \mathrm{H}^{+}$ per $\left.\mathrm{Ti}_{3} \mathrm{C}_{2} \mathrm{O}_{2}\left(\mathrm{H}_{2} \mathrm{O}\right)_{1.33}\right)$. On the contrary, the $c$-lattice parameter generally increases with $\mathrm{H}^{+}$ intercalation into the $\mathrm{Ti}_{3} \mathrm{C}_{2}(\mathrm{OH})_{2}\left(\mathrm{H}_{2} \mathrm{O}\right)_{1.33}$ supercell, with the most significant increase occurring from 0.88 to $1.11 \mathrm{H}^{+}$. In this supercell, with the intercalation of $20 \mathrm{H}^{+}$, the $c$-lattice expanded by $1.32 \AA$ A. Although these values did not fit perfectly with the experimental data, DFT simulations confirmed that the $c$-lattice can either expand or shrink upon $\mathrm{H}^{+}$intercalation depending on the surface termination.

The change in $c$-lattice parameter can originate from a change in either the interlayer distance or the monolayer thickness (as defined in Figure S2). Figure 4 shows the calculated change in the interlayer distances and the monolayers thicknesses. No significant changes of the monolayer's thicknesses were observed, confirming that the expansion and shrinkage of the $c$ lattice were due to change in the interlayer distance.

Considering cyclic voltammograms, in-situ XRD and DFT results, as well as equation 1 and previous in-situ Raman results, ${ }^{[1]}$ a credible hypothesis on energy storage mechanism of $\mathrm{H}^{+}$ 
into $\mathrm{Ti}_{3} \mathrm{C}_{2} \mathrm{~T}_{\mathrm{x}}$ may be that (1) between $-0.25 \mathrm{~V}$ and $0 \mathrm{~V} v s$. Ag there is electrochemical double layer mechanism, without significant lattice parameter change, (2) then below $-0.25 \mathrm{~V} \mathrm{vs.} \mathrm{Ag,}$ proton insertion and redox reaction start converting some O-terminations to $\mathrm{OH}$-terminations along electrostatic shrinking, as was observed with several other cations, ${ }^{[6]}(3)$ then upon further proton insertion and the second redox reaction below $-0.5 \mathrm{~V} v s$. Ag, which converts more Oterminations to $\mathrm{OH}$-terminations, the $c$-lattice parameter increases due longer bonds and electrostatic repulsion from similarly charged $\mathrm{OH}$-terminated surface of MXenes sheets.

\section{Conclusions}

This work investigated the change of the $c$-lattice parameter of two-dimensional titanium carbide $\left(\mathrm{Ti}_{3} \mathrm{C}_{2} \mathrm{~T}_{\mathrm{x}}\right.$ MXene) upon $\mathrm{H}^{+}$intercalation. The study conducted leads to a better understanding of the pseudocapacitive mechanism. According to collected data, the charge storage in sulfuric acid appeared to be more complex than previously thought. In-situ XRD demonstrated that there is a fluctuating expansion/shrinkage phenomenon during charge and discharge. For example, upon charging from 0 to $-0.6 \mathrm{~V} v s$. Ag, the lattice can shrink by $0.1 \AA$, then from -0.6 to $-0.9 \mathrm{~V} v s$. Ag it can expand by $0.5 \AA$. This definitely demonstrates the pseudointercalation charge storage mechanism of $\mathrm{Ti}_{3} \mathrm{C}_{2} \mathrm{~T}_{\mathrm{x}}$ in acidic electrolyte. This type of charge storage mechanism can provide a higher energy density than double layer capacitance. Additionally, DFT simulations trends showed that $\mathrm{Ti}_{3} \mathrm{C}_{2}$ with O-termination shrinks upon $\mathrm{H}^{+}$ intercalation, whereas $\mathrm{Ti}_{3} \mathrm{C}_{2}$ with $\mathrm{OH}$-termination expanded. As the real surface chemistry of $\mathrm{Ti}_{3} \mathrm{C}_{2} \mathrm{~T}_{\mathrm{x}}$ is a combination of both $\mathrm{O}$ and $\mathrm{OH}$ terminations, these results are supporting the insitu XRD data.

The volume change necessary during the electrochemical cycle might be one of causes of the diffusion limitation observed in restacked $\mathrm{Ti}_{3} \mathrm{C}_{2} \mathrm{~T}_{\mathrm{x}}$ electrodes. This supports the theory that designing $\mathrm{Ti}_{3} \mathrm{C}_{2} \mathrm{~T}_{\mathrm{x}}$ electrodes with sufficient interlayer distance to allow intercalation of $\mathrm{H}^{+}$ without lattice deformation may enable a higher rate (power) supercapacitor, and explain 
enhanced performances observed with $\mathrm{Ti}_{3} \mathrm{C}_{2} \mathrm{~T}_{\mathrm{x}}$ electrodes with spacer between layers or different morphologies. ${ }^{[8,18]}$ As it is the largest reversible volume change observed in MXenes for aqueous supercapacitors, these results suggest better performance for actuator applications compared to other aqueous electrolytes. ${ }^{[19]}$ Finally, these results could also be relevant for other pseudocapacitive materials, including other MXenes, such as $\mathrm{Mo}_{2} \mathrm{CT}_{\mathrm{x}}, \mathrm{Mo}_{1.33} \mathrm{CT}_{\mathrm{x}}$, and $\mathrm{V}_{2} \mathrm{CT}_{\mathrm{x}}{ }^{[20]}$

\section{Experimental Section}

Synthesis of $\mathrm{Ti}_{3} \mathrm{C}_{2} \mathrm{Tx}$ MXene:

Following $\mathrm{Ti}_{3} \mathrm{C}_{2} \mathrm{Tx}$ minimally intensive layer delamination (MILD) method previously reported $^{[21]}$, an etching solution containing lithium fluoride $(0.8 \mathrm{~g})$ in hydrochloric acid $(10 \mathrm{~mL}$, $9 \mathrm{M})$ was prepared under continuous stirring and $\mathrm{Ti}_{3} \mathrm{AlC}_{2}(0.5 \mathrm{~g})$ powder (400 mesh, purchased from Jilin 11technology Co.) was slowly added to the solution. The etching reaction was carried out at room temperature for 24 hours. The obtained material was washed with deionized $\mathrm{H}_{2} \mathrm{O}$ via repeated centrifugation until $\mathrm{pH}>5$, then delamination of $\mathrm{Ti}_{3} \mathrm{C}_{2} \mathrm{Tx}$ nanosheets was achieved by vigorous hand shaking for 10 minutes.

\section{In-situ electrochemical XRD:}

A slurry of the MILD $\mathrm{Ti}_{3} \mathrm{C}_{2} \mathrm{Tx}$ MXene was obtained via centrifugation at $10000 \mathrm{rpm}$ and coated on a glassy carbon electrode. After drying at room temperature overnight, the resulting binder-free $\mathrm{Ti}_{3} \mathrm{C}_{2} \mathrm{~T}_{\mathrm{x}}$ film had solid adhesion to the glassy carbon and was used as working electrode. The counter electrode was over capacitive activated carbon, containing $5 \mathrm{wt}$ \% PTFE, and the reference electrode was $\mathrm{Ag}$ wire (calibrated potential of $\mathrm{Ag}$ wire is $-0.3 \mathrm{~V} v s$. $\mathrm{Hg} / \mathrm{Hg}_{2} \mathrm{SO}_{4}$ ). Following this, the electrodes were placed in modified 3-electrode cell, represented Figure S3, filled with $1 \mathrm{M} \mathrm{H}_{2} \mathrm{SO}_{4}$ and covered with a Kapton window to avoid electrolyte evaporation while allowing XRD recording. Cyclic voltammetry at $0.2 \mathrm{mV} \mathrm{s}^{-1}$ was performed to control the working electrode potential using an Ivium Technologies B.V vertex. 
one. XRD patterns of the $\mathrm{Ti}_{3} \mathrm{C}_{2} \mathrm{~T}_{\mathrm{x}}$ electrode during cycling was collected on a Brucker D8 diffractometer using a $\mathrm{Cu} \mathrm{K \alpha}$ radiation $(\lambda=1.5406 \AA)$ in the range $2 \theta=5-20^{\circ}$ with a step of $0.01^{\circ}$. Calculation of the number of intercalated protons from capacitance values

The approximate number of cations intercalated into an active material can be calculated according to Equation 2:

$$
\delta=\frac{C \times \Delta V \times M}{F}
$$

where: $\delta$ is the number of $\mathrm{H}^{+}$intercalated, $C$ is the gravimetric capacitance $\left(\mathrm{F} \mathrm{g} \mathrm{g}^{-1}\right), \Delta V$ is the potential range $(\mathrm{V}), M$ is the molar mass of $\mathrm{Ti}_{3} \mathrm{C}_{2} \mathrm{~T}_{\mathrm{x}}\left(\mathrm{g} \mathrm{mol}^{-1}\right)$, and $F$ is the Faraday constant (96485 $\left.\mathrm{C} \mathrm{mol}^{-1}\right)$.

\section{Density Functional Theory Simulation}

First-principles calculations were performed in the framework of DFT as implemented in the Vienna ab initio simulation package (VASP). ${ }^{[22]}$ For the exchange-correlation energy, we used the Perdue-Burke-Ernzerhof version of the generalized gradient approximation. ${ }^{[23]}$ The projector-augmented wave potential was used with a plane-wave cutoff energy of $600 \mathrm{eV} .^{[24]}$ The Van der Waals (VdW)-inclusive DFT-D3 method was used for all simulations. ${ }^{[25]}$ The underlying structural optimizations were performed using the conjugate gradient method, and the convergence criterion was set to $10^{-6} \mathrm{eV} /$ cell in energy and $0.01 \mathrm{eV} /$ in force.

\section{Supporting Information}

Supporting Information is available from the Wiley Online Library or from the author.

\section{Acknowledgements}

Xinpeng $\mathrm{Mu}$ and Dashuai Wang contributed equally to this work. This work was financially supported by Science \& Technology Department of Jilin Province (No. 20180101199JC, 20180101204JC), Jilin Province/Jilin University Co-construction Project - Funds for New Materials (SXGJSF2017-3), and the Thousand Talents program (China).

Received: ((will be filled in by the editorial staff))

Revised: ((will be filled in by the editorial staff)) Published online: ((will be filled in by the editorial staff)) 


\section{References}

[1] P. Simon, Y. Gogotsi, Nat. Mater. 2008, 7, 845.

[2] a) B. E. Conway, Electrochemical supercapacitors: scientific fundamentals and technological applications, Springer Science \& Business Media, 1999; b) V. Augustyn, P. Simon, B. Dunn, Energy Environ. Sci. 2014, 7, 1597.

[3] M. Naguib, M. Kurtoglu, V. Presser, J. Lu, J. Niu, M. Heon, L. Hultman, Y. Gogotsi, M. W. Barsoum, Adv. Mat. 2011, 23, 4248.

[4] B. Anasori, M. R. Lukatskaya, Y. Gogotsi, Nat. Rev. Mat. 2017, 2, 16098.

[5] H. Wang, Y. Wu, X. Yuan, G. Zeng, J. Zhou, X. Wang, J. W. Chew, Adv. Mat. 2018, $30,1704561$.

[6] M. R. Lukatskaya, O. Mashtalir, C. E. Ren, Y. Dall'Agnese, P. Rozier, P. L. Taberna, M. Naguib, P. Simon, M. W. Barsoum, Y. Gogotsi, Science 2013, 341, 1502.

[7] a) Y. Dall'Agnese, P. Rozier, P.-L. Taberna, Y. Gogotsi, P. Simon, J. Power Sources 2016, 306, 510; b) Z. Lin, P. Rozier, B. Duployer, P.-L. Taberna, B. Anasori, Y. Gogotsi, P. Simon, Electrochem. Commun. 2016, 72, 50.

[8] M. R. Lukatskaya, S. Kota, Z. F. Lin, M. Q. Zhao, N. Shpigel, M. D. Levi, J. Halim, P. L. Taberna, M. Barsoum, P. Simon, Y. Gogotsi, Nat. Energy 2017, 2, 6.

[9] M. D. Levi, M. R. Lukatskaya, S. Sigalov, M. Beidaghi, N. Shpigel, L. Daikhin, D. Aurbach, M. W. Barsoum, Y. Gogotsi, Adv. Energy Mater. 2015, 5, 1400815.

[10] M.-Q. Zhao, C. E. Ren, Z. Ling, M. R. Lukatskaya, C. Zhang, K. L. Van Aken, M. W. Barsoum, Y. Gogotsi, Adv. Mat. 2015, 27, 339.

[11] M. Hu, Z. Li, T. Hu, S. Zhu, C. Zhang, X. Wang, ACS Nano 2016, 10, 11344.

[12] C. Zhan, M. Naguib, M. Lukatskaya, P. R. C. Kent, Y. Gogotsi, D.-e. Jiang, J. Phys. Chem. Lett. 2018, 9, 1223.

[13] Y. Xie, Y. Dall'Agnese, M. Naguib, Y. Gogotsi, M. W. Barsoum, H. L. Zhuang, P. R. C. Kent, ACS Nano 2014, 8, 9606. 
[14] Y. Dall'Agnese, M. R. Lukatskaya, K. M. Cook, P. L. Taberna, Y. Gogotsi, P. Simon, Electrochem. Commun. 2014, 48, 118.

[15] M. Ghidiu, J. Halim, S. Kota, D. Bish, Y. Gogotsi, M. W. Barsoum, Chem. Mat. 2016, $28,3507$.

[16] X. Xie, M.-Q. Zhao, B. Anasori, K. Maleski, C. E. Ren, J. Li, B. W. Byles, E. Pomerantseva, G. Wang, Y. Gogotsi, Nano Energy 2016, 26, 513.

[17] N. Shpigel, M. D. Levi, S. Sigalov, T. S. Mathis, Y. Gogotsi, D. Aurbach, J. Am. Chem. Soc. 2018, 140, 8910 .

[18] a) M. Boota, B. Anasori, C. Voigt, M.-Q. Zhao, M. W. Barsoum, Y. Gogotsi, Adv. Mat. 2016, 28, 1517; b) Y. Xia, T. S. Mathis, M.-Q. Zhao, B. Anasori, A. Dang, Z. Zhou, H. Cho, Y. Gogotsi, S. Yang, Nature 2018, 557, 409.

[19] J. Come, J. M. Black, M. R. Lukatskaya, M. Naguib, M. Beidaghi, A. J. Rondinone, S. V. Kalinin, D. J. Wesolowski, Y. Gogotsi, N. Balke, Nano Energy 2015, 17, 27.

[20] a) J. Halim, S. Kota, M. R. Lukatskaya, M. Naguib, M. Q. Zhao, E. J. Moon, J. Pitock, J. Nanda, S. J. May, Y. Gogotsi, M. W. Barsoum, Adv. Funct. Mater. 2016, 26, 3118; b) Q. Z. Tao, M. Dahlqvist, J. Lu, S. Kota, R. Meshkian, J. Halim, J. Palisaitis, L. Hultman, M. W. Barsoum, P. O. A. Persson, J. Rosen, Nat. Commun. 2017, 8, 7; c) Q. Shan, X. Mu, M. Alhabeb, C. E. Shuck, D. Pang, X. Zhao, X.-F. Chu, Y. Wei, F. Du, G. Chen, Y. Gogotsi, Y. Gao, Y. Dall'Agnese, Electrochem. Commun. 2018, 96, 103.

[21] M. Alhabeb, K. Maleski, B. Anasori, P. Lelyukh, L. Clark, S. Sin, Y. Gogotsi, Chem. Mat. 2017, 29, 7633.

[22] G. Kresse, J. Furthmüller, Phys. Rev. B 1996, 54, 11169.

[23] J. P. Perdew, K. Burke, M. Ernzerhof, Phys. Rev. Lett. 1996, 77, 3865.

[24] G. Kresse, D. Joubert, Phys. Rev. B 1999, 59, 1758.

[25] S. Grimme, J. Antony, S. Ehrlich, H. Krieg, J. Chem. Phys. 2010, 132, 154104. 

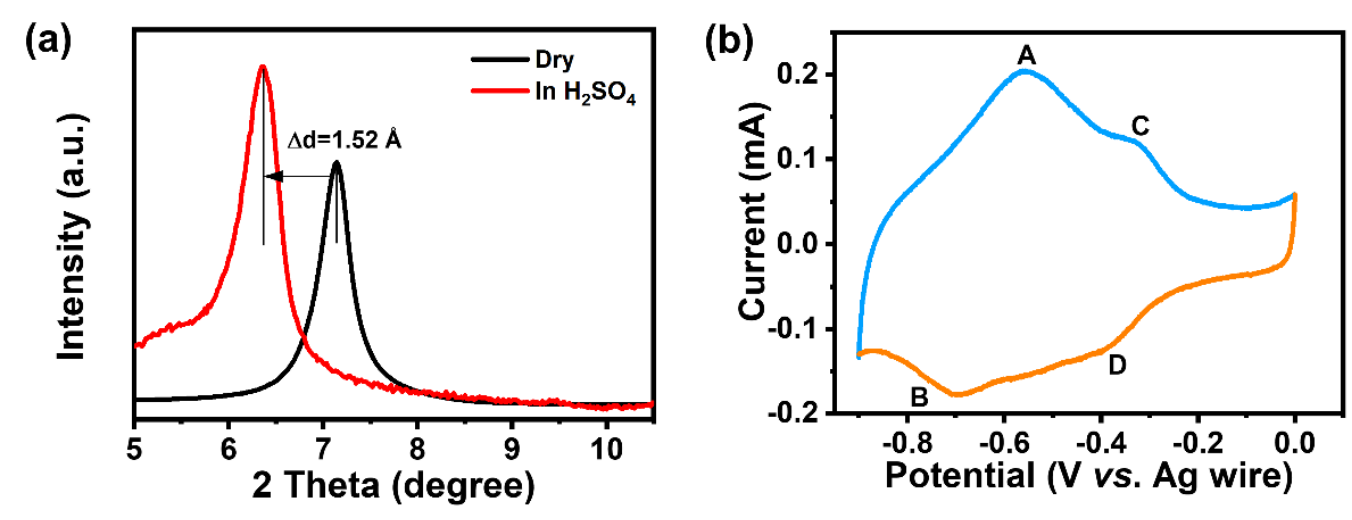

(c)

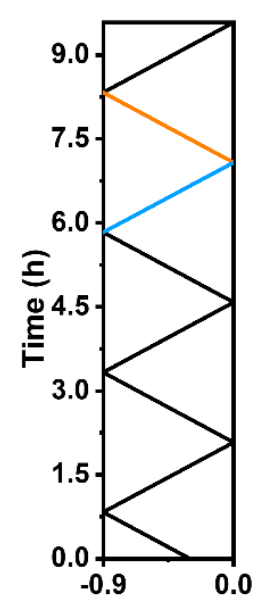

(002)

In-situ XRD cell (006)
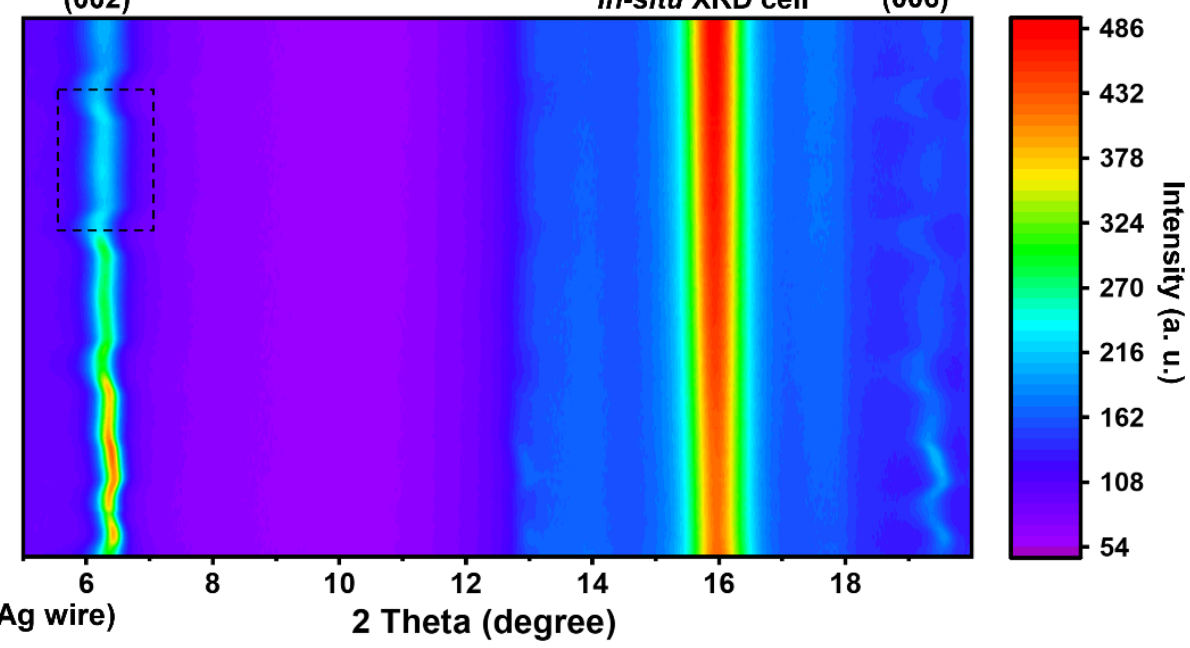

Potential (V vs. Ag wire)
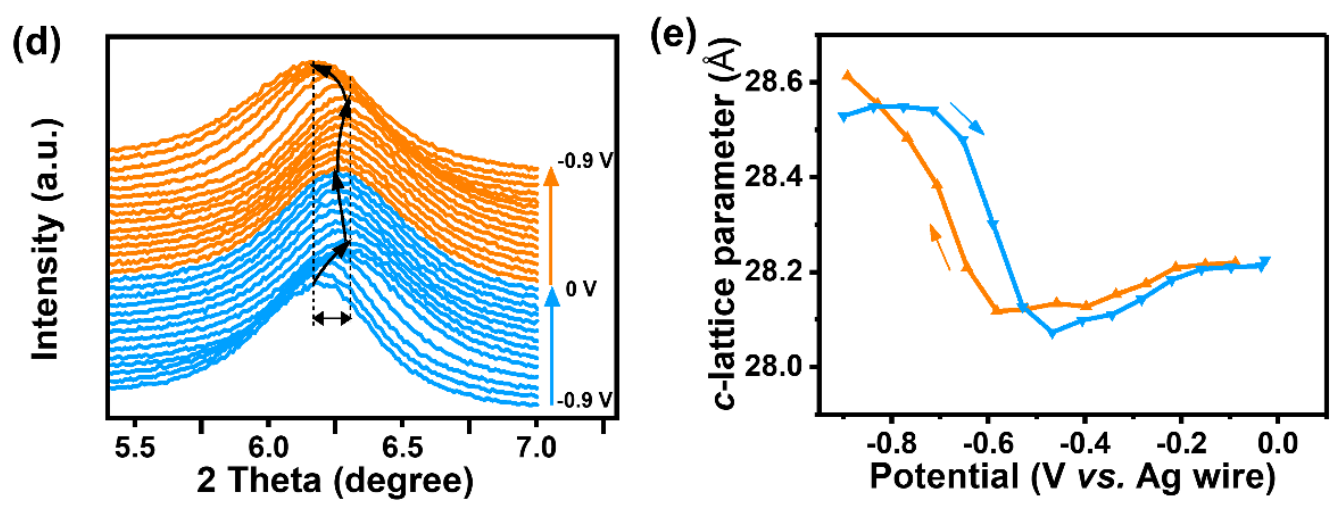

Figure 1. (a) XRD patterns of $\mathrm{Ti}_{3} \mathrm{C}_{2} \mathrm{~T}_{\mathrm{x}}$ dry and immersed in $1 \mathrm{M} \mathrm{H}_{2} \mathrm{SO}_{4}$. Electrochemical insitu X-Ray Diffraction study of $\mathrm{Ti}_{3} \mathrm{C}_{2} \mathrm{~T}_{\mathrm{x}}$ in $1 \mathrm{M} \mathrm{H}_{2} \mathrm{SO}_{4}$ : (b) Cyclic voltammogram at $0.2 \mathrm{mV} \mathrm{s}$ ${ }^{1}$. (c-d) In-situ XRD patterns during electrochemical cycle. (e) Change of the $c$-lattice parameter with potential. 
(a) $\mathrm{Ti}_{3} \mathrm{C}_{2} \mathrm{O}_{2}$

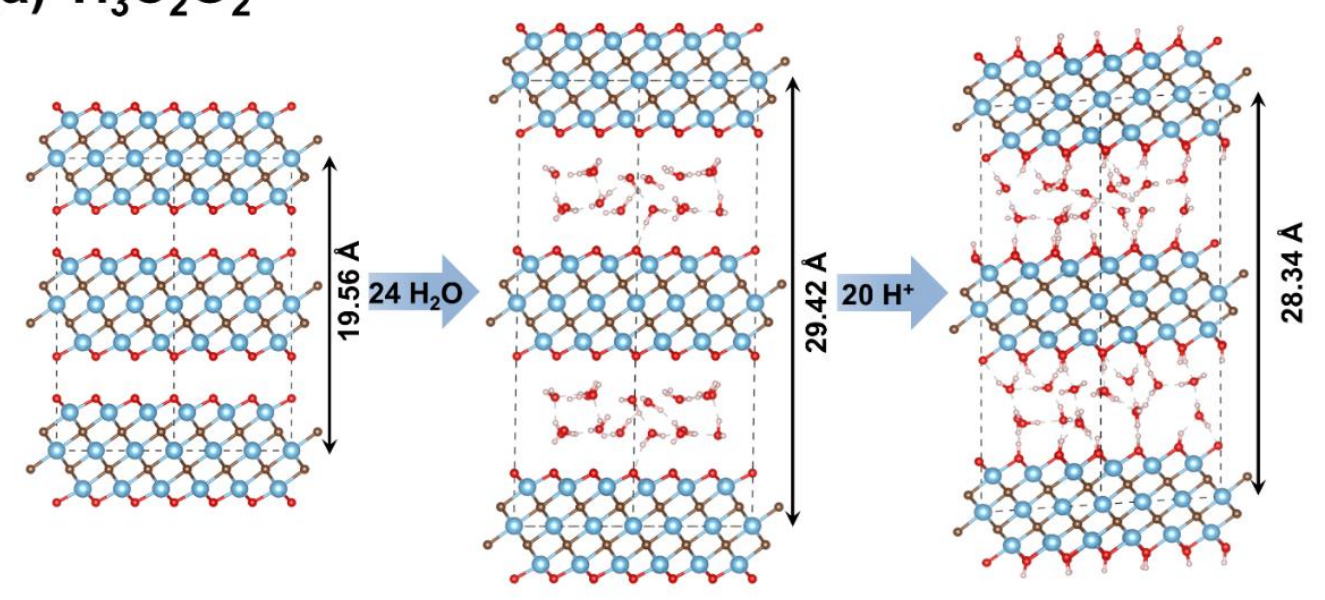

(b) $\mathrm{Ti}_{3} \mathrm{C}_{2}(\mathrm{OH})_{2}$

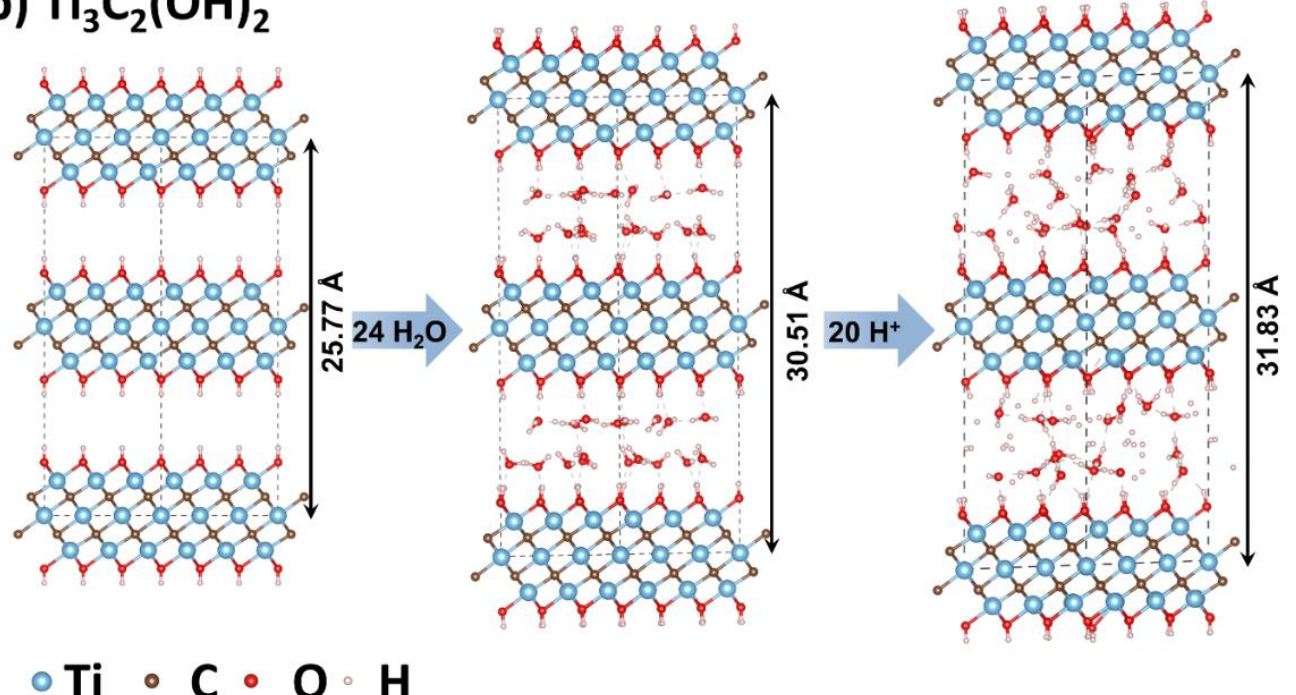

Figure 2. Simulation of $\mathrm{H}_{2} \mathrm{O}$ and $\mathrm{H}^{+}$intercalation into (a) $\mathrm{Ti}_{3} \mathrm{C}_{2} \mathrm{O}_{2}$ and (b) $\mathrm{Ti}_{3} \mathrm{C}_{2}(\mathrm{OH})_{2}$ supercells. 
(a)

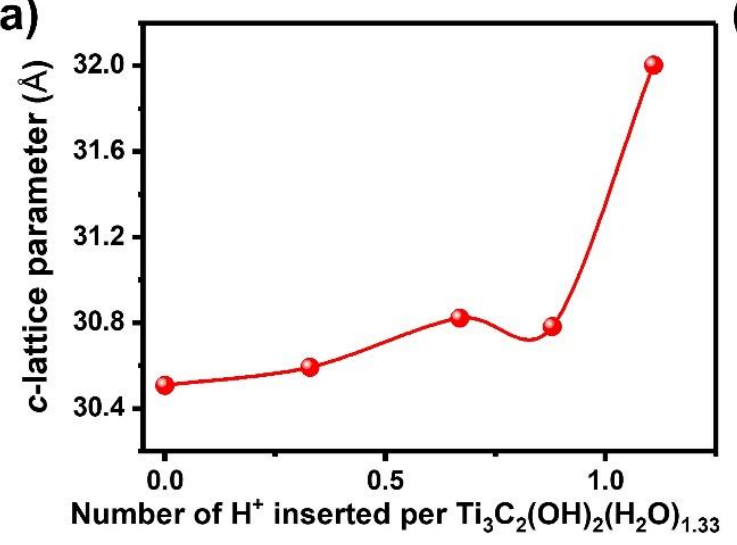

(b)

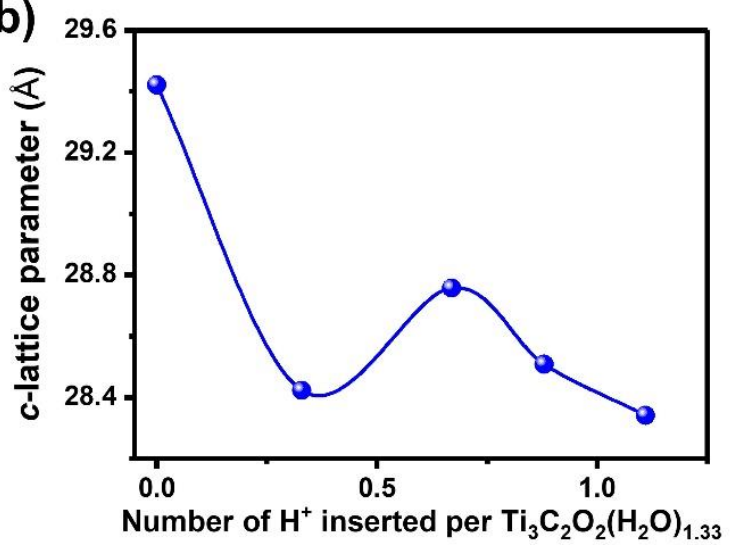

Figure 3. Change of the $c$-lattice parameter upon $\mathrm{H}^{+}$insertion into (b) $\mathrm{Ti}_{3} \mathrm{C}_{2}(\mathrm{OH})_{2}\left(\mathrm{H}_{2} \mathrm{O}\right)_{1.33}$ and into (c) $\mathrm{Ti}_{3} \mathrm{C}_{2} \mathrm{O}_{2}\left(\mathrm{H}_{2} \mathrm{O}\right)_{1.33}$ supercells.

(a)

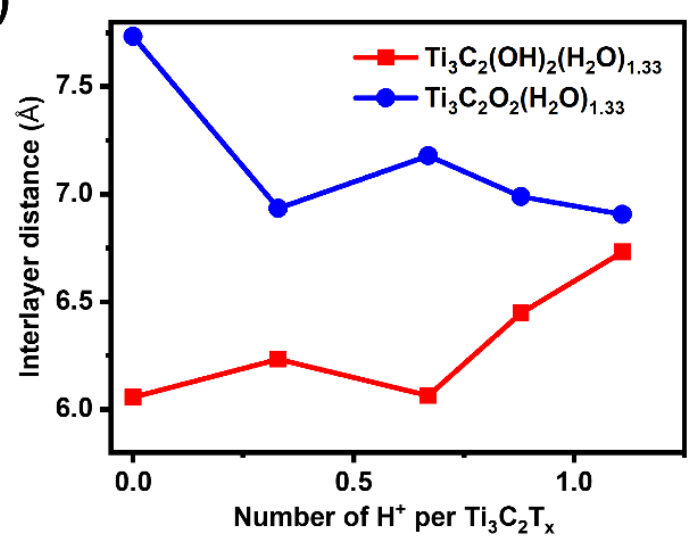

(b)

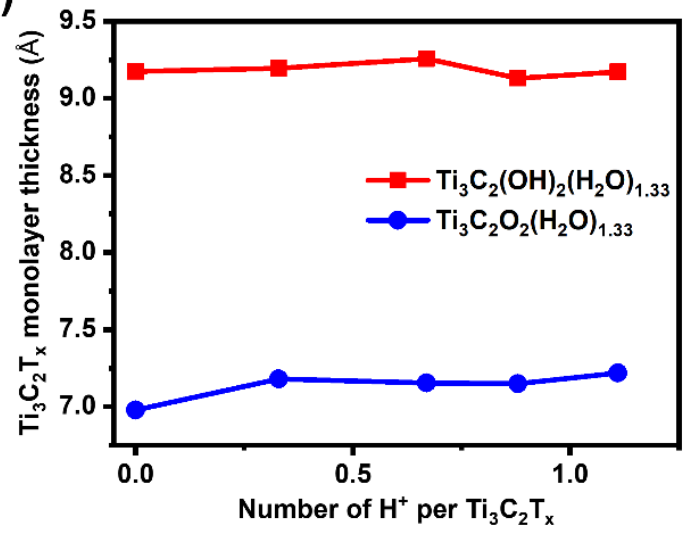

Figure 4. (a) Interlayer distance and (b) monolayer thickness upon $\mathrm{H}^{+}$insertion into $\mathrm{Ti}_{3} \mathrm{C}_{2}(\mathrm{OH})_{2}\left(\mathrm{H}_{2} \mathrm{O}\right)_{1.33}$ and $\mathrm{Ti}_{3} \mathrm{C}_{2} \mathrm{O}_{2}\left(\mathrm{H}_{2} \mathrm{O}\right)_{1.33}$ supercells 


\section{The table of contents entry:}

$\mathrm{Ti}_{3} \mathrm{C}_{2} \mathbf{T}_{\mathrm{x}}$, a two-dimensional titanium carbide belonging to the large family of MXenes, has quickly attracted attention as a promising electrode for supercapacitors with acidic electrolyte. Herein, in-situ X-ray diffraction and density functional theory calculation are used to investigate the $c$-lattice parameter changes during cycling in $1 \mathrm{M} \mathrm{H}_{2} \mathrm{SO}_{4}$. The charge storage mechanism is revealed to be a two-step pseudo-intercalation.

Keyword Supercapacitors

Xinpeng Mu, Dashuai Wang, Fei Du, Gang Chen, Chunzhong Wang, Yingjin Wei, Yury Gogotsi*, Yu Gao*, Yohan Dall'Agnese*

Revealing the pseudo-intercalation charge storage mechanism of MXenes in acidic electrolyte

Table of Content (size: $55 \mathrm{~mm}$ broad $\times 50 \mathrm{~mm}$ high):

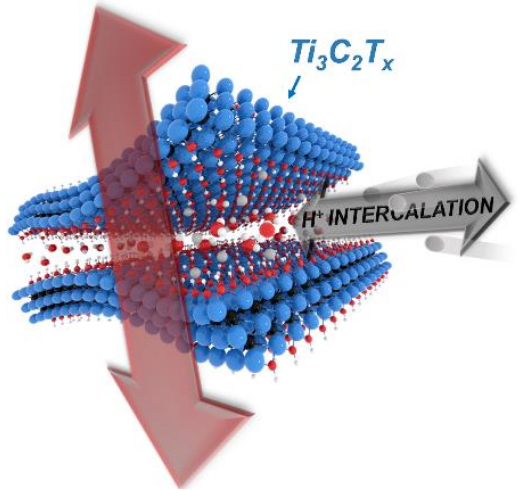


Copyright WILEY-VCH Verlag GmbH \& Co. KGaA, 69469 Weinheim, Germany, 2016.

\section{Supporting Information}

Revealing the pseudo-intercalation charge storage mechanism of MXenes in acidic electrolyte

Xinpeng Mu, Dashuai Wang, Fei Du, Gang Chen, Chunzhong Wang, Yingjin Wei, Yury Gogotsi*, Yu Gao*, Yohan Dall'Agnese*
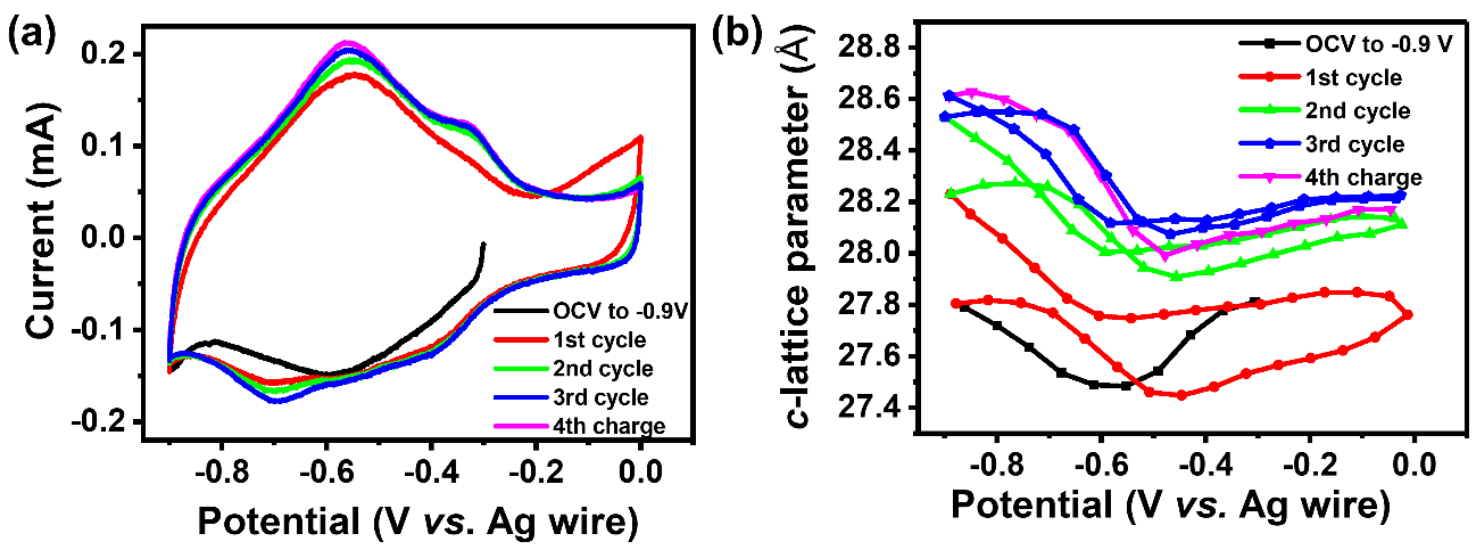

Figure S1. In-situ XRD test: (a) cyclic voltammograms and (b) $c$-lattice parameters. 


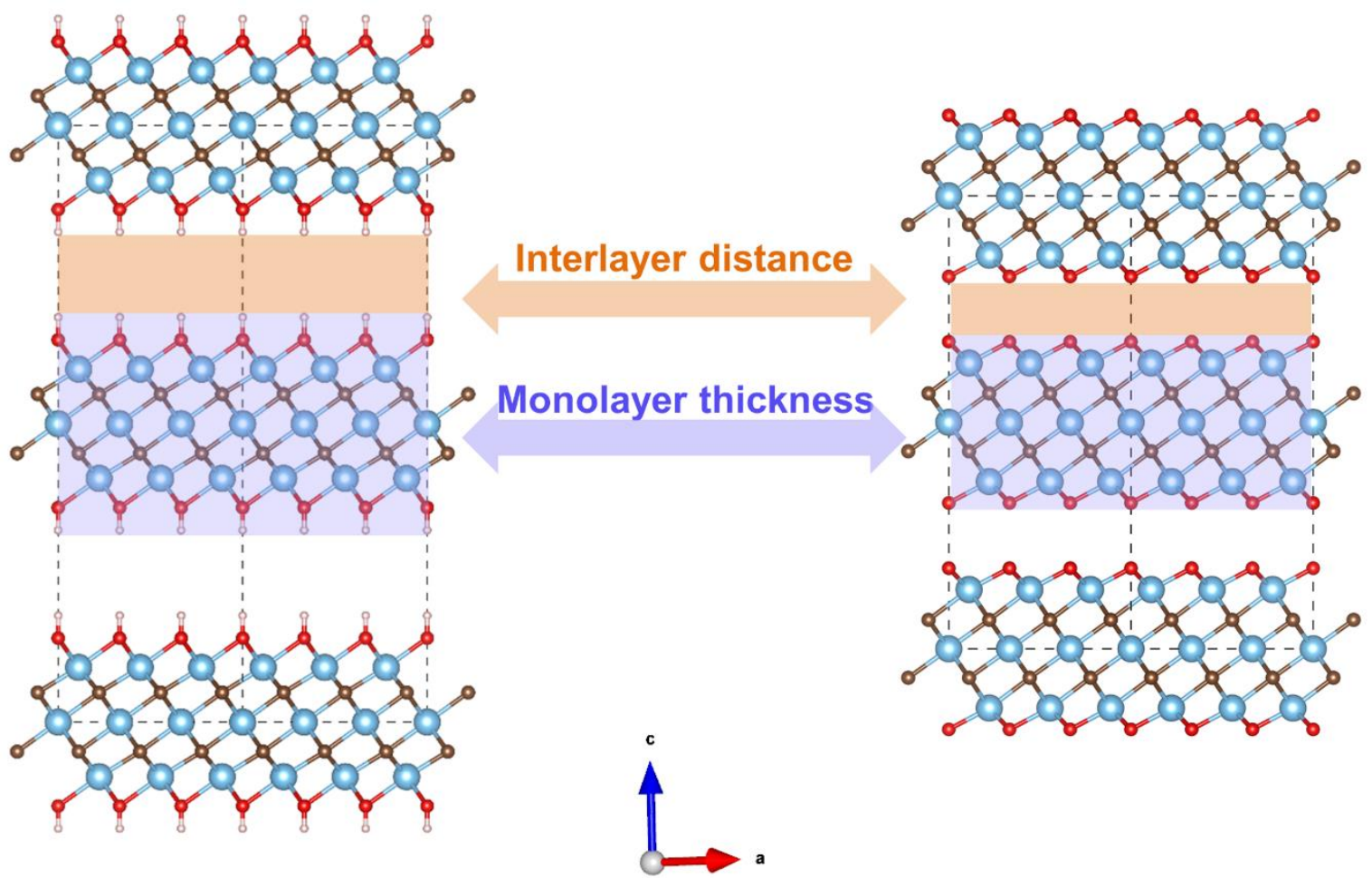

Figure S2. Schematic of interlayer distance and monolayer thickness definition.

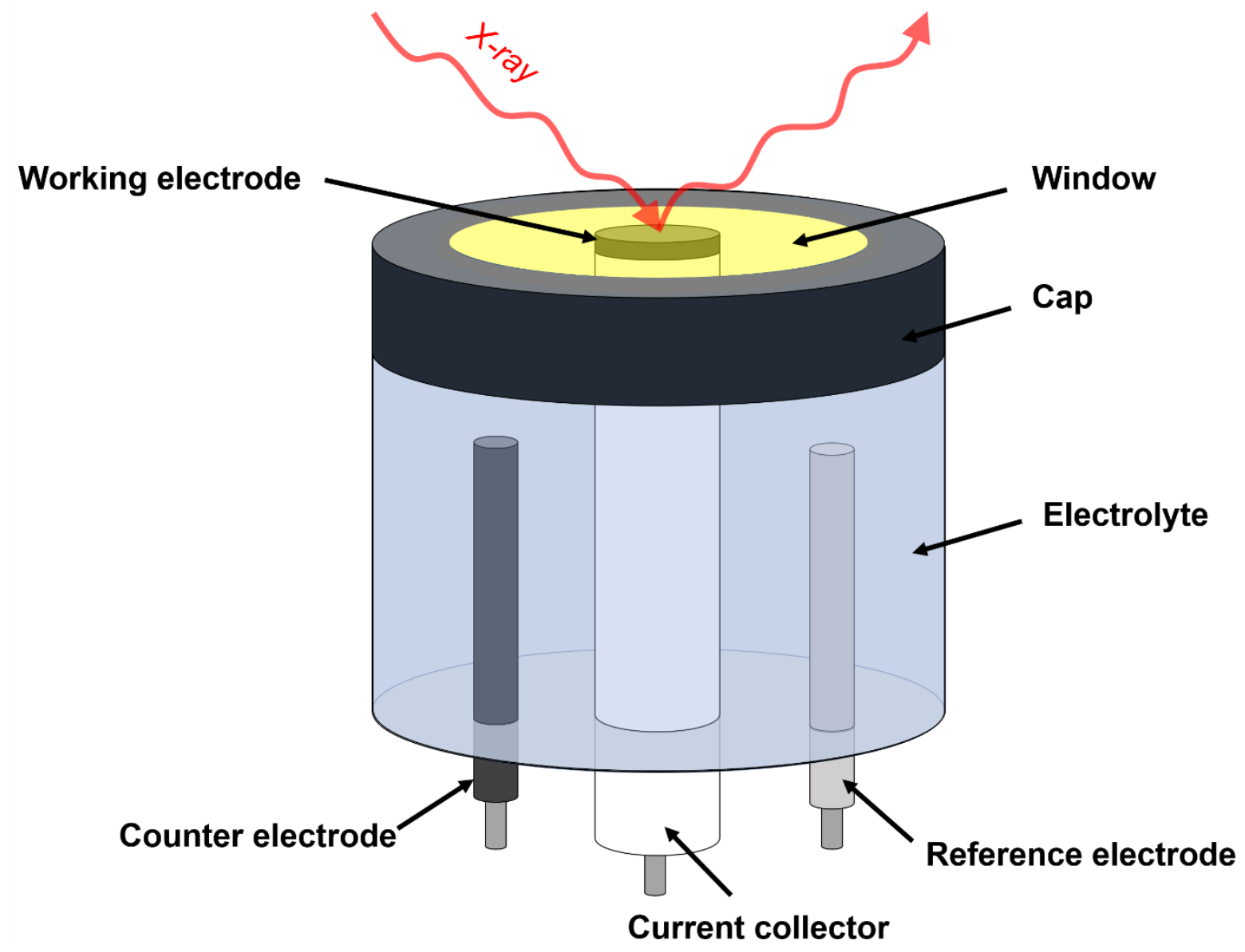

Figure S3. Schematic representation of the in-situ XRD cell. 